NASA-CR-201441

Reprinted from MONThly Weather Review, Vol. 123, No. 8, August 1995

American Meteorological Society

\title{
A Diagnosis of the Development of a Winter Anticyclone over North America
}

\author{
Melinda L. King, * Phillip J. Smith, and Anthony R. Lupo \\ Department of Earth and Atmospheric Sciences, Purdue University, West Lafayette, Indiana
}

(Manuscript received 13 May 1994, in final form 22 August 1994)

\begin{abstract}
This paper examines the 48 -h life cycle of a winter anticyclone occurring over North America from 18 to 20 January 1979 using Goddard Laboratory for Atmospheres FGGE level IIIb (SOP 1) global analyses on a $4^{\circ}$ latitude by $5^{\circ}$ longitude grid. Applying the relatively new methodology of the Zwack-Okossi equation, results show that anticyclonic vorticity advection and cold-air advection acted to develop the anticyclone, while adiabatic warming in the descending air opposed development. Other forcing processes made only small contributions to anticyclone changes. Vertical profiles of the development quantities reveal that vorticity and temperature advections, as well as the adiabatic warming, maximized in the $200-300$-mb layer.
\end{abstract}

\section{Introduction}

As noted recently by Tan and Curry (1993), migrating midlatitude anticyclones have been studied much less than have their low pressure counterparts, extratropical cyclones, probably due to their association with "fair weather" conditions. However, understanding the development and movement of such anticyclones is important because of their contributions to the general circulation and to potential air pollution accumulation. Migrating anticyclones, when coupled with cyclones, form the transient waves of the general circulation, which in turn are largely responsible for day-to-day weather changes experienced in the midlatitudes. These high pressure areas involve downward vertical air movement, which results in stable air and the absence of precipitation. Thus, when such phenomena become slow moving, or even stationary, for several days and occur over areas of significant pollution emission, air pollution problems can result.

Wexler ( 1951 ) summarized the early meteorological literature pertaining to anticyclones, which he then classified into groups identified as cold, warm, or mixed. Significant radiative forcing appears to be largely confined to cold anticyclone development (e.g., Curry 1983, 1987). However, other forcing mechanisms have been noted in all anticyclone types. Among these are upper-level velocity convergence, identified

\footnotetext{
* Current affiliation: Texas Natural Resources Conservation Commission, Austin, Texas.

Corresponding author address: Prof. Phillip J. Smith, Department of Earth and Atmospheric Sciences, Purdue University, 1397 Civil Engineering Bldg., West Lafayette, IN 47907-1397.
}

as a forcing mechanism itself or in association with anticyclonic vorticity advection (Bodurtha 1952; Bowling et al. 1968; Dallavalle and Bosart 1975; Boyle and Bosart 1983; Tan and Curry 1993) and cold-air advection (Fleagle 1947; Bodurtha 1952; Boyle and Bosart 1983; Tan and Curry 1993).

The principal objective of this study is to add to the limited body of literature that currently exists regarding the development and decay of midlatitude migrating anticyclones. This objective is accomplished by studying the synoptic-scale forcing mechanisms present during the life cycle of an anticyclone system that occurred over North America from 0000 UTC 18 January to 0000 UTC 20 January 1979 using a relatively new methodology known as the Zwack-Okossi equation (Zwack and Okossi 1986; Lupo et al. 1992). Indeed, a test of the utility of this diagnostic approach for an anticyclone system can be regarded as a secondary objective of the study. This event was chosen because it afforded the opportunity to study a significant winter anticyclone that experienced both growth and decay over a relatively short time period.

\section{Synoptic discussion}

The horizontal and vertical structure of the anticyclone system is summarized using sea level pressure, 850 -mb height and temperature, 500 -mb height and relative vorticity, and 300-mb height and wind speed maps.

The anticyclone of interest here began at 0000 UTC 18 January over Ontario, Canada, west of James Bay (Fig. 1a) with a central sea level pressure of $1028 \mathrm{mb}$. The anticyclone continued to develop and by $12 \mathrm{~h}$ later had moved southward across Ontario southwest of James Bay with a central pressure of $1037 \mathrm{mb}$ (Fig. 2a). By 0000 UTC 19 January, the anticyclone had 

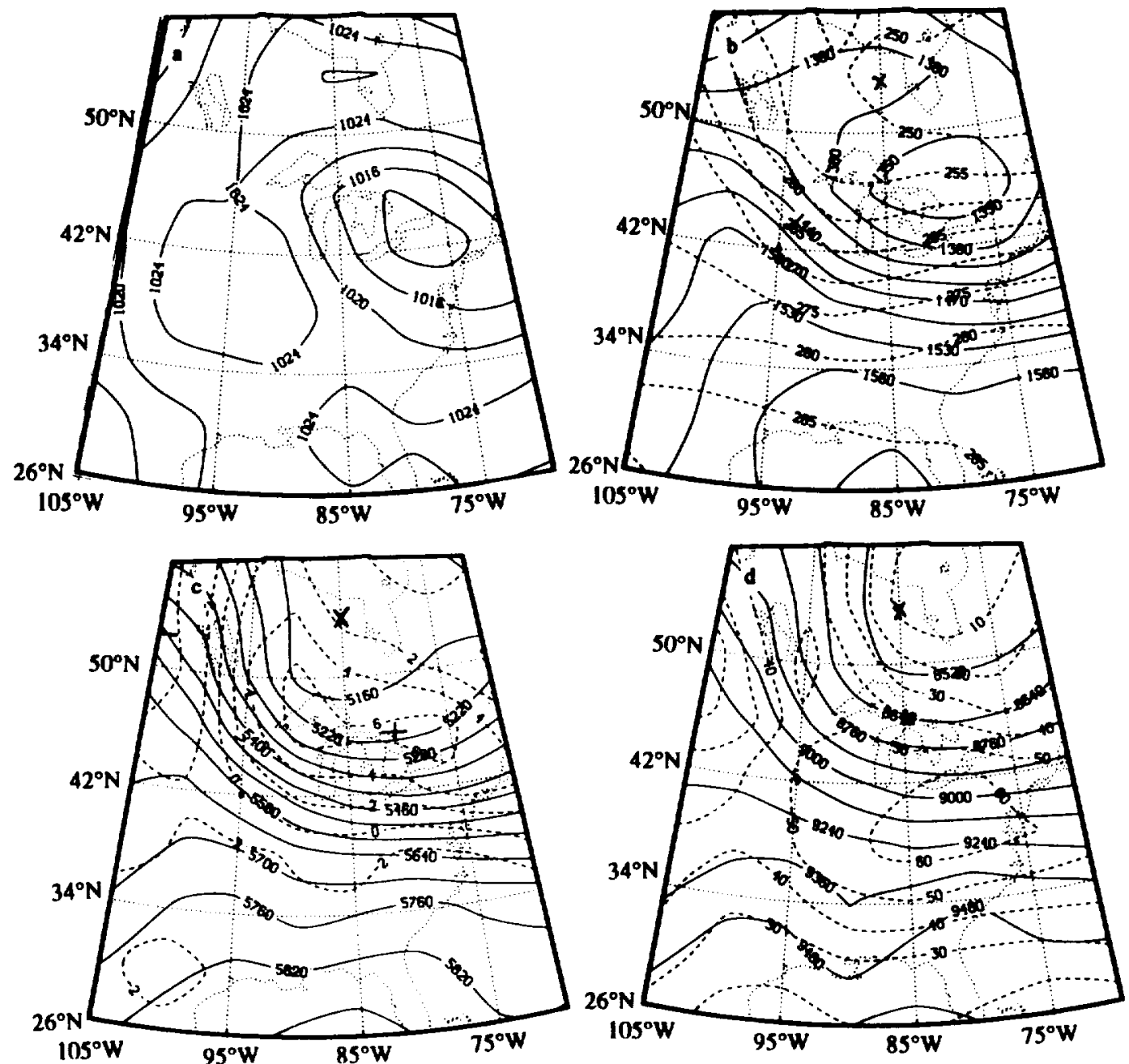

FIG 1 Observed (a) sea level pressure ( $4 \mathrm{mb}$, solid), (b) 850 - $\mathrm{mb}$ heights ( $30 \mathrm{~m}$, solid) and temperatures ( $5 \mathrm{~K}$, dashed), (c) 500 -mb heights $\left(60 \mathrm{~m}\right.$, solid) and relative vorticities $\left(2 \times 10^{5} \mathrm{~s}^{-1}\right.$, dashed), and (d) $300-\mathrm{mb}$ heights ( $120 \mathrm{~m}$, solid) and wind speeds $\left(10 \mathrm{~m} \mathrm{~s}^{-1}\right.$. dashed) for 0000 UTC 18 January 1979. The cross denotes the grid point with maximum sea level pressure.

matured to a central pressure of $1038 \mathrm{mb}$ while moving eastward due south of James Bay (Fig. 3a). Over the next $12 \mathrm{~h}$, the decaying anticyclone, at $1035 \mathrm{mb}$, continued its eastward propagation into western Quebec (Fig. 4a). By the final map time, 0000 UTC 20 January, the anticyclone had propagated northeastward to western Quebec just east of James Bay with a central pressure of $1029 \mathrm{mb}$ (Fig. 5a).

The surface anticyclone is associated with a doubleridge system in the upper-air fields, a northern ridge extending northeastward across the anticyclone center, and a southern ridge over the central and eventually eastern United States. At $850 \mathrm{mb}$, the temperature wave (Fig. 1b) was out of phase with the height field, suggesting a baroclinic wave with warm-air advection west and cold-air advection east of the ridge system. The southern ridge intensified over the next 12 h (Fig. 2b) as it moved eastward to a position $5^{\circ}$ west of the surface ridge. The thermal pattern became more out of phase with the height field, thus enhancing the low-level temperature advections. By 0000 UTC 19 January (Fig. $3 \mathrm{~b}$ ), the ridge amplitude maximized over the central midwestern and southern United States, while the thermal pattern remained similar to the previous map time. During the last two map times (Figs. $4 b-5 b$ ), the ridge over the eastem United States damped as it moved to a position above the surface ridge. The thermal wave also weakened during this period. The 850 -mb ridge height and thermal structure was similar to that reported by Boyle and Bosart (1983).

The 500-mb ridge system at 0000 UTC 18 January (Fig. Ic) lagged the surface anticyclone. During the next $24 \mathrm{~h}$ (Figs. $2 \mathrm{c}-3 \mathrm{c}$ ), the amplifying ridge moved eastward to a position over the central United States, re- 

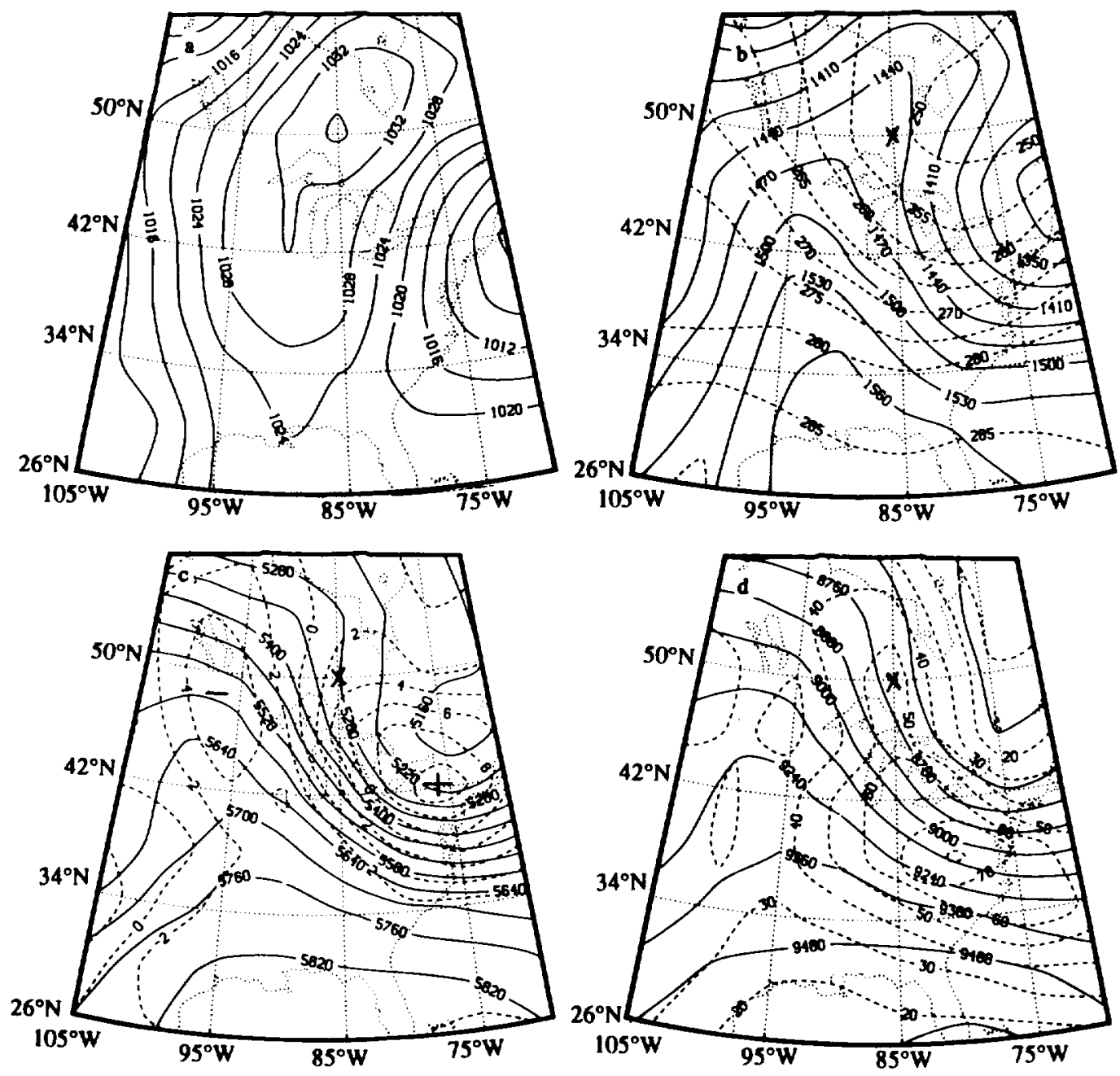

Fig. 2. As in Fig. 1 for 1200 UTC 18 January 1979.

maining west of the surface system. Then, over the last 24 hours (Figs. $4 c-5 c$ ) the ridge system damped as it moved to a position nearly above the surface anticyclone center and ridge. Through the first four map times the surface anticyclone features were positioned downstream from a 500 -mb relative vorticity minimum of about $-4 \times 10^{-5} \mathrm{~s}^{-1}$. By 1200 UTC 19 January the vorticity minimum had shifted south of Lake Erie, and the anticyclone center was located just downstream from a weaker vorticity minimum axis. The relative positions of the $500-\mathrm{mb}$ vorticity minima and the surface anticyclone system were similar to those reported by Boyle and Bosart (1983) and Tan and Curry (1993).

The 300-mb ridge locations were similar to those at $500 \mathrm{mb}$ and also followed the same amplification and decay sequence (Figs. 1-5d). The other interesting feature to note is the location of the surface features relative to the $300-\mathrm{mb}$ jet. Throughout the study period, the surface anticyclone center was positioned on the cyclonic side of the 300-mb jet, which Boyle and Bo- sart ( 1983) noted as a characteristic of a cold-core anticyclone, and upstream from the jet maximum. Its position relative to the jet maximum, its cold core, and its relatively low tropopause $(\sim 300 \mathrm{mb})$ allow this event to be classified as a cold anticyclone.

\section{The Zwack-Okossi equation}

The primary diagnostic equation used in this paper is a relatively new expression known as the Zwack-Okossi $(\mathrm{Z}-\mathrm{O})$ equation. This equation is a generalized form of the Petterssen-Sutcliffe equation (Petterssen 1956, p. 324) that diagnoses the geostrophic vorticity tendency at a near-surface pressure level as forced by a set of processes integrated through the entire vertical air column. Furthermore, the geostrophic vorticity tendency fields so determined can be relaxed to obtain near-surface geopotential height tendencies. Originally developed in quasigeostrophic form by Zwack and Okossi ( 1986), the Z$\mathrm{O}$ equation was recently developed in both generalized and "extended" forms by Lupo et al. (1992). 

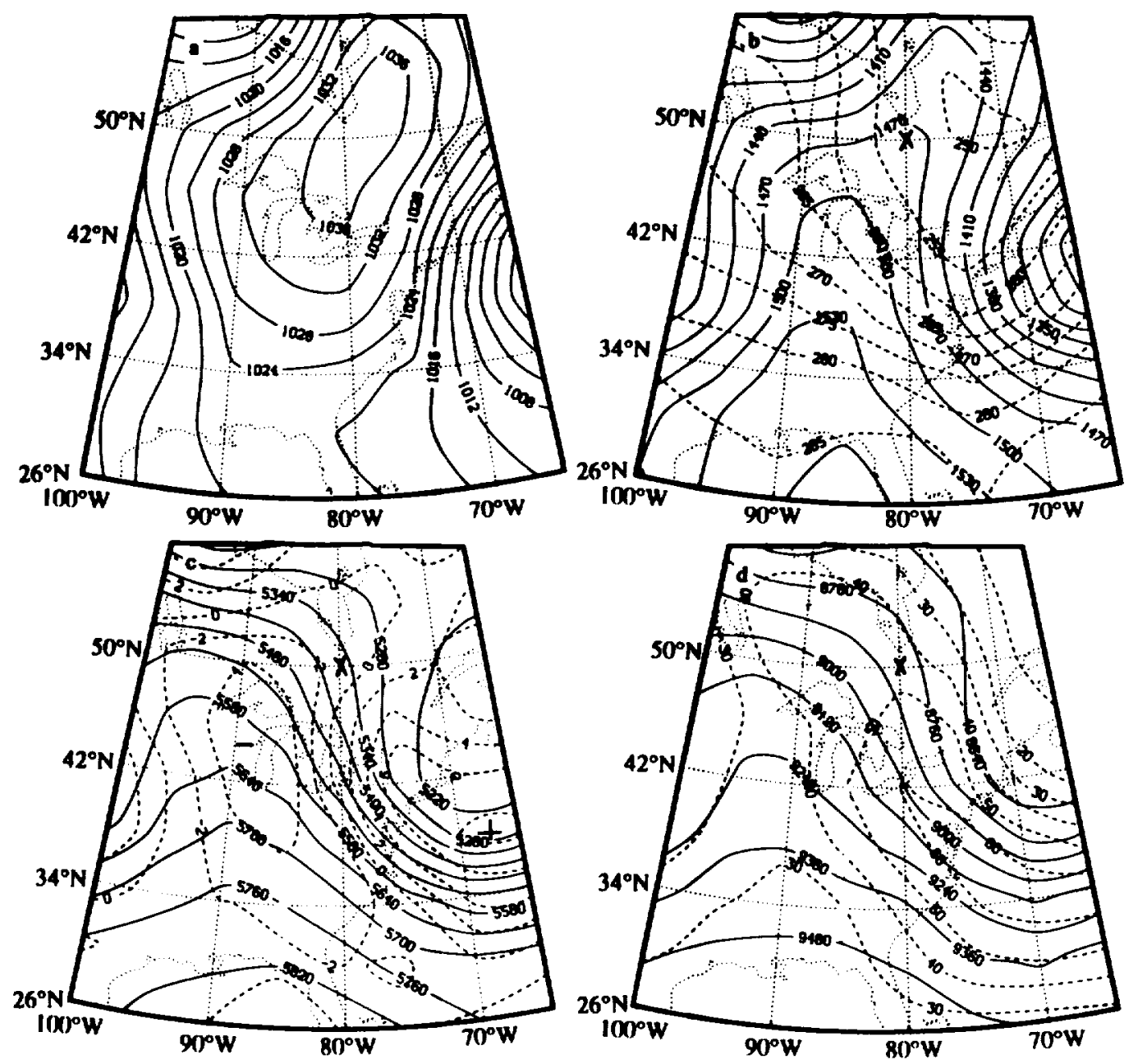

FIG. 3. As in Fig. 1 for 0000 UTC 19 January 1979.

Briefly, the development proceeds by taking the twodimensional Laplacian on an isobaric surface $\left(\nabla^{2}\right)$ and Eulerian time derivative $(\partial / \partial t)$ of the hydrostatic balance equation to yield

$$
\frac{\partial \zeta_{g l}}{\partial t}=\frac{\partial \zeta_{g}}{\partial t}-\frac{R}{f} \int_{p}^{p_{l}} \frac{\partial \nabla^{2} T}{\partial t} \frac{d p}{p},
$$

where $\zeta_{8}$ is the geostrophic relative vorticity $\left(g f^{-1} \nabla^{2} z\right)$, $T$ is the temperature, $p$ is the pressure, $R$ is the dry-air gas constant, and $f$ is the Coriolis parameter. The subscript $l$ refers to the near-surface pressure level. Representing $\partial \zeta_{g} / \partial t$ as the difference between the actual vorticity tendency $(\partial \zeta / \partial t)$ and the ageostrophic vorticity tendency $\left(\partial \zeta_{\mathrm{ag}} / \partial t\right)$, substituting for $\partial \zeta / \partial t$ and $\partial T / \partial t$ using the vorticity equation and first law of thermodynamics, respectively, and integrating from $p_{t}$ to an upperlevel $p_{t}$ that is sufficiently high to include most of the atmospheric mass while still providing usable data yields the generalized expression [see Eq. (9) in Lupo et al. 1992]. As noted in Lupo et al., it is appropriate for stud- ies of large-scale circulations to simplify the generalized expression based on scale analysis and many sample calculations of individual terms. This yields the "extended" form of the $\mathrm{Z}-\mathrm{O}$ equation

$$
\begin{aligned}
& \frac{\partial \zeta_{g l}}{\partial t}=\operatorname{Pd} \int_{p_{t}}^{p_{t}}-\mathbf{V} \cdot \nabla \zeta_{d} d p \\
& -\operatorname{Pd} \int_{p_{t}}^{p_{t}}\left[\frac{R}{f} \int_{p}^{p_{t}} \nabla^{2}\left(-\mathbf{V} \cdot \nabla T+\frac{\dot{Q}}{c_{p}}+S \omega\right) \frac{d p}{p}\right] d p \\
& \text { (B) } \quad \text { (C) } \quad \text { (D) } \\
& +\operatorname{Pd} \int_{p_{t}}^{p_{t}} \mathbf{k} \cdot \nabla \times \mathbf{F} d p
\end{aligned}
$$

where $\mathrm{Pd}=\left(p_{l}-p_{t}\right)^{-1}, \zeta_{a}$ the absolute vorticity, $\mathbf{V}$ is the horizontal wind vector, $\omega$ is the vertical motion in isobaric coordinates $(d p / d t), \dot{Q}$ is the diabatic heating rate, $F$ is the frictional force, and $S$ is the static stability 

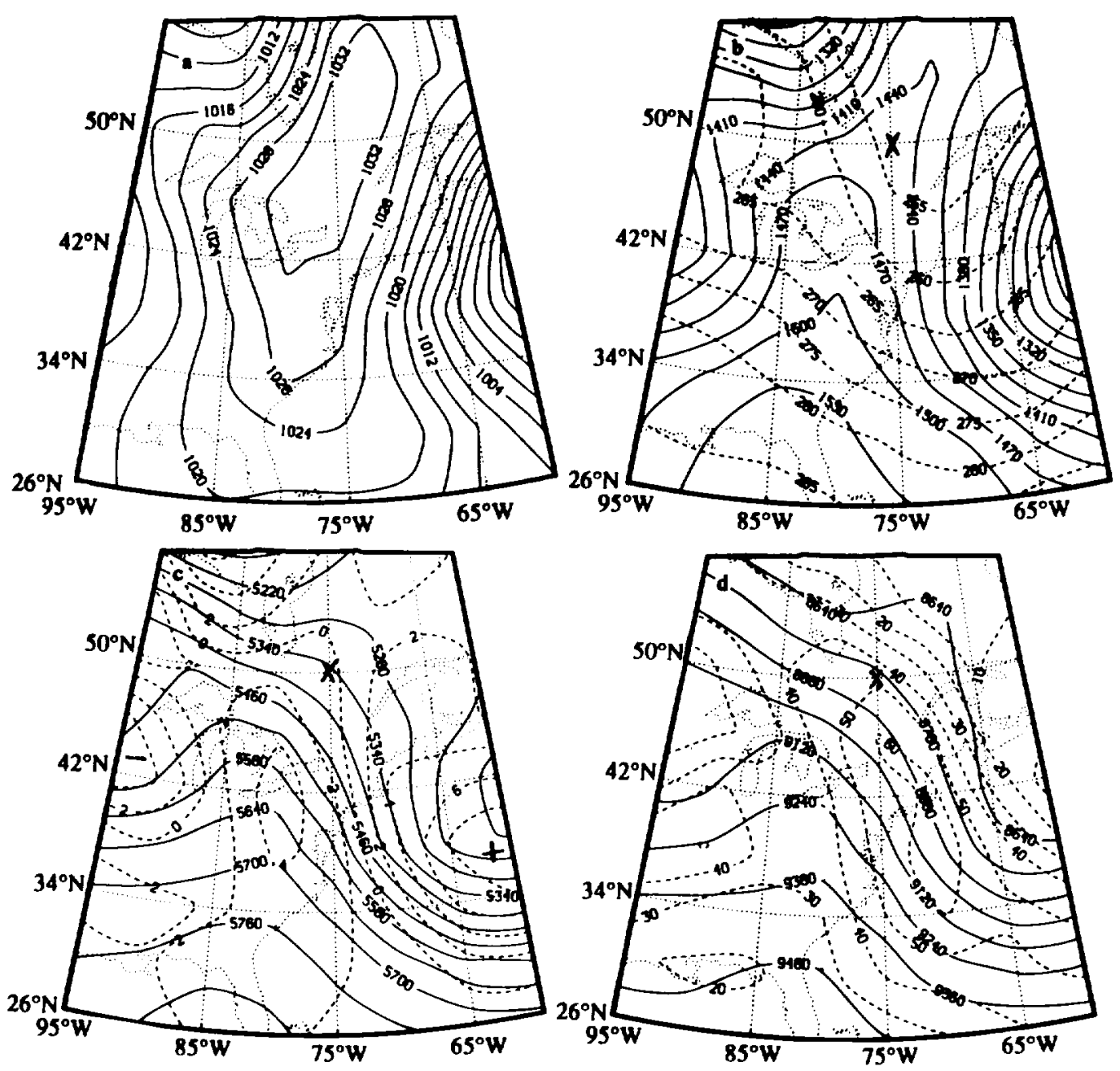

Flg. 4. As in Fig. 1 for 1200 UTC 19 January 1979.

parameter $[=-(T / \theta)(\partial \theta / \partial p)], \theta$ is potential temperature). Equation ( 2 ) is so-named following the terminology of Tsou et al. (1987) in their treatment of the height tendency equation. The implication is that the quasigeostrophic form is extended to include the influence of nonquasigeostrophic forcing in the right-handside terms. In all terms of $(2)$ the integrand of the $p_{t^{-}}$ $p$, integral represents the horizontal divergence forced by each process at level $p$. Term A (VADV) represents local divergence (convergence) that is produced as the atmosphere readjusts to a spatially varying, geostrophically balanced state in response to local cyclonic (anticyclonic) vorticity advection. Terms B (TADV), C, and $\mathrm{D}$ (ADIA) represent heating (cooling) processes that force horizontally nonuniform upward (downward) displacements of the pressure surfaces above the heating (cooling) maximum, resulting in local horizontal divergence (convergence). Term E (FRIC), which is restricted to the boundary layer in this paper, represents the divergence or convergence forced by frictional processes. Term $\mathrm{C}$ includes the effects of latent heat release (LATH), infrared radiation (IRCH), and boundary layer sensible heating (SENS). Note that the $\mathrm{Z}-\mathrm{O}$ equation explicitly includes both dynamic and thermal forcing processes at all levels above the developing surface feature.

\section{Computational methods \\ a. Data and finite differencing}

The Goddard Laboratory for Atmospheres (GLA) 6-h interval special observation period 1 level IIIb analyses of the FGGE level IIb dataset (Baker 1983) were used for this research. This study utilized as its computational domain the portion of the original GLA global analyses extending from $22^{\circ}$ to $82^{\circ} \mathrm{N}$ and $0^{\circ}$ to $120^{\circ} \mathrm{W}$. This domain covers approximately all of North America and adjacent portions of the North Atlantic Ocean. Mandatory-level data were interpo- 


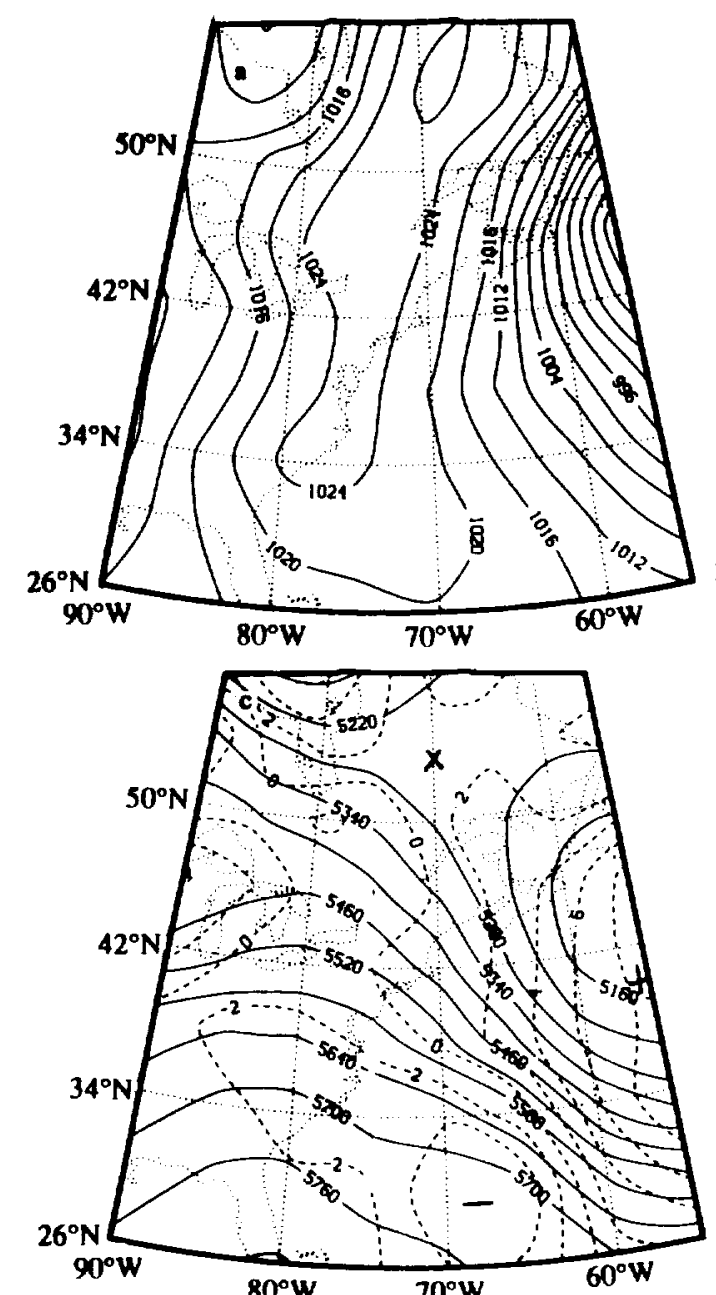

Fici. 5. As in Fig. 1 for 0000 UTC 20 January 1979
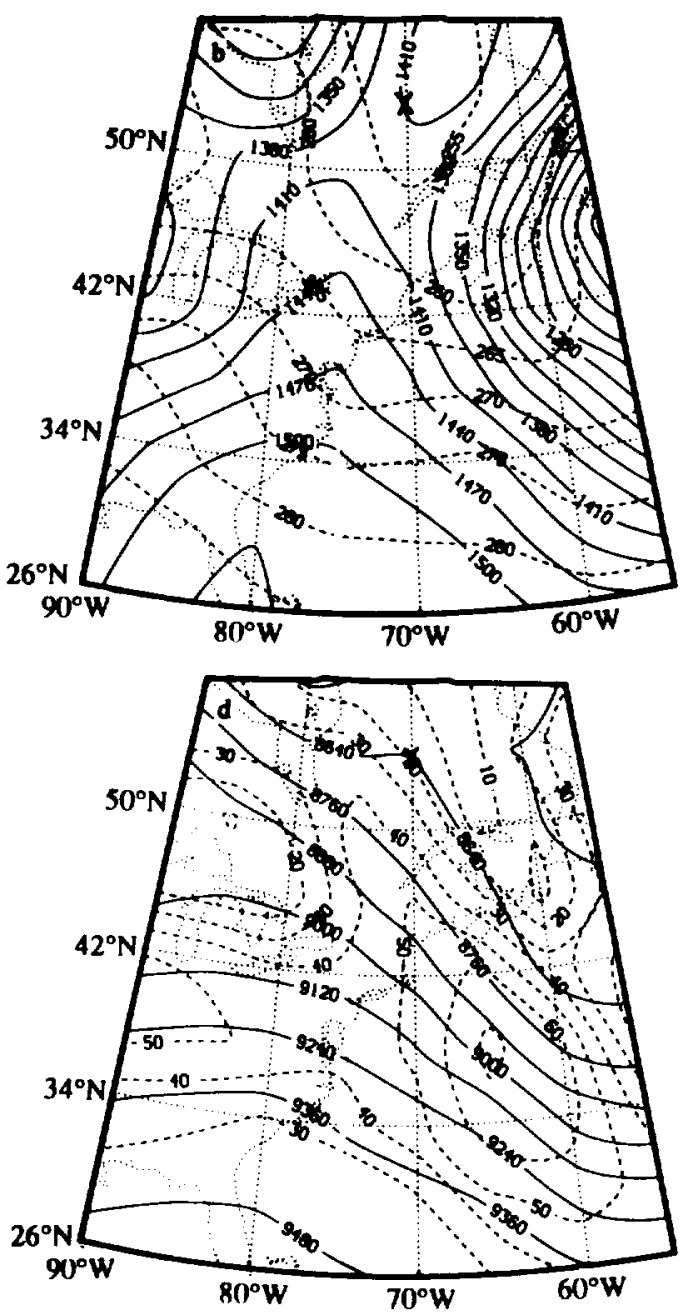

lated or extrapolated to standard isobaric surfaces from 1050 to $50 \mathrm{mb}$ in $50-\mathrm{mb}$ increments. The horizontal resolution is $4^{\circ}$ latitude by $5^{\circ}$ longitude.

The results presented are confined to moving domains extending over $32^{\circ}$ latitude and $35^{\circ}$ longitude in order to focus on the evolution of the surface anticyclone previously described. The vertical computational domain extends from the near-surface level $\left(p_{l}\right)$, defined as the first $50-\mathrm{mb}$ layer above the surface (always either 1000 or $950 \mathrm{mb}$ ), to an upper limit of $100 \mathrm{mb}$. The near-surface level was so defined in order to specify a pressure level that was always above the surface but was sufficiently close to the surface to be representative of surface anticyclogenesis.

The $\mathrm{Z}-\mathrm{O}$ equation calculations applied second-order finite differencing to determine all derivatives and the trapezoidal rule for the evaluation of vertical integrals. Geopotential height tendencies were obtained by twodimensional sequential overrelaxation of the geo- strophic vorticity tendencies with zero initial and lateral boundary values. Relaxation was terminated when the absolute difference between two successive iterations was less than $10^{-5} \mathrm{~m} \mathrm{~s}^{-1}$ at all grid points for the VADV, TADV, ADIA, and LATH terms and $10^{-6}$ $\mathrm{m} \mathrm{s}^{-1}$ for the remaining terms. Relaxation of the thermodynamic terms followed the application of the horizontal smoothing operator discussed in Lupo et al. (1992). In order to identify the tendency quantities with development (i.e., where the propagation contribution to the tendency would be expected to be small), results are also summarized for the anticyclone center. Vertical motions were determined using an extended form of the omega equation ( see Tsou et al. 1987; Lupo et al. 1992) with $\omega$ set to zero at the surface and $50 \mathrm{mb}$.

\section{b. Diabatic heating and frictional processes}

Latent heat release, sensible heating, and boundary layer frictional processes were obtained using the pro- 
cedures described in Lupo et al. (1992). Infrared radiation was determined using Sasamori's (1968) scheme with a water vapor emissivity correction suggested by Ramanathan et al. (1983). This scheme, which contains the effects of water vapor, carbon dioxide, and ozone, determines the longwave cooling rates as the difference between integrated upward and downward radiative fluxes in a cloudless atmosphere. To account for clouds, a randomly overlapping scheme developed by Harshvardhan et al. (1987) was utilized. A cloud was assumed to exist at any point that had a latent heat value greater than zero.

\section{c. Comparison procedures}

Mean absolute values (MAV) and correlation coefficients (CC) were employed to statistically compare calculated $\mathrm{Z}-\mathrm{O}$ with observed geopotential height tendencies. The observed tendencies were estimated as 12-h finite differences centered on the period from $6 \mathrm{~h}$ before to $6 \mathrm{~h}$ after each map time. The mean absolute value is the mean of the absolute value of the height tendencies over all grid points. All statistics were computed for the anticyclone domains represented in Figs. 6 and 7. These statistics were also averaged over the complete time period from 0000 UTC 18 January to 0000 UTC 20 January 1979.

\section{Comparison of observed and $\mathrm{Z}-\mathrm{O}$ tendencies}

An integrated view of the comparability of observed near-surface geopotential height changes (OBS) with $\mathrm{Z}-\mathrm{O}$ equation values $(\mathrm{Z}-\mathrm{O}$ ) using MAV and CC statistics is given in Table 1 . Results indicate that the observed tendencies averaged over the 48 -h period are approximately $17 \%$ larger in magnitude than the $\mathrm{Z}-\mathrm{O}$ tendencies at the near-surface level. The larger percentage differences at 0000 UTC 19 January occurred because of underestimates of $\mathrm{Z}-\mathrm{O}$ height falls in the wake of the anticyclone in the western portion of the domain. At 0000 UTC 20 January, the difference can be largely attributed to the placement of the $\mathrm{Z}-\mathrm{O}$ height rise maximum one grid interval too far east and thus partially outside of the domain represented in the Table 1 statistics. In neither case is the anticyclone diagnosis compromised. Furthermore, the correlation coefficients $(\geqslant 0.786)$ suggest good pattern comparability between the two fields at all times.

To examine both the magnitude and pattern comparability further, comparisons of the two fields are made for 1200 UTC on both 18 and 19 January (Fig. $6)$. These map times were selected because they correspond to the midpoint of both the development and decay phases of the surface anticyclone. At 1200 UTC 18 January, the near-surface $\mathrm{OBS}$ and $\mathrm{Z}-\mathrm{O}$ patterns and magnitudes are very similar, with a particularly good match in the area of the height increases over the eastern Great Lakes. The near-surface OBS and Z-O tendencies patterns are also quite similar at 1200 UTC 19 January. The OBS and Z-O maxima are located over the Atlantic Ocean at about $40^{\circ} \mathrm{N}, 65^{\circ} \mathrm{W}$ with an OBS maximum that is $28 \%$ larger than the $\mathrm{Z}-\mathrm{O}$. The patterns and magnitudes are sufficiently similar to conclude that the $\mathrm{Z}-\mathrm{O}$ model provides reliable height tendency estimates for the surface anticyclone.

\section{Diagnostic results}

\section{a. Basic forcing processes}

In the interest of brevity, the discussion in this section is restricted to the two map times noted above. Furthermore, maps of individual forcing contributions (Fig. 7) are restricted to those that most consistently dominate the anticyclone evolution, the horizontal vorticity and temperature advections, and the adiabatic warming. Other forcing processes are examined at the anticyclone center in the next two sections.

At 1200 UTC 18 January, midway through the period of anticyclone pressure rise, an area of height increases encompassed the surface center, which was northwest of the total tendency maximum (see upperright panel in Fig. 6). Figure 7 (left-hand panels) reveals that these height increases were largely forced by integrated anticyclonic vorticity and cold-air advections. The combination of these two processes was sufficient to offset the influence of adiabatic warming found within the descending air associated with the anticyclone. During the anticyclone decay period, as represented by the 1200 UTC 19 January field (lower right panel in Fig. 6), the surface anticyclone center was positioned near the zero tendency isopleth, again northwest but farther removed from the total height rise maximum.

\section{b. Anticyclone center averages}

Recall that anticyclone center values ( see section 4a) are used to isolate the development component of the height tendency. In order to summarize the relative contribution of the different terms, a quantity referred to as the "development sum," formed by adding the terms that contribute to anticyclone development (positive height tendencies), was computed for the 48-h average statistics. All terms, including those that resulted in negative tendencies, were then evaluated relative to this sum.

The 48-h average total height tendency (ZTOT) for the anticyclone center (Fig. 8, top) was $0.69 \times 10^{-3}$ $\mathrm{m} \mathrm{s}^{-1}$. The development was clearly dominated by horizontal anticyclonic vorticity and cold-air advections, which contributed $68 \%$ and $27 \%$, respectively, to the development sum of $2.37 \times 10^{-3} \mathrm{~m} \mathrm{~s}^{-1}$. The primary balancing process was adiabatic warming, which was $59 \%$ of the development sum. All other terms were small, reflecting the small values typical of these quan- 

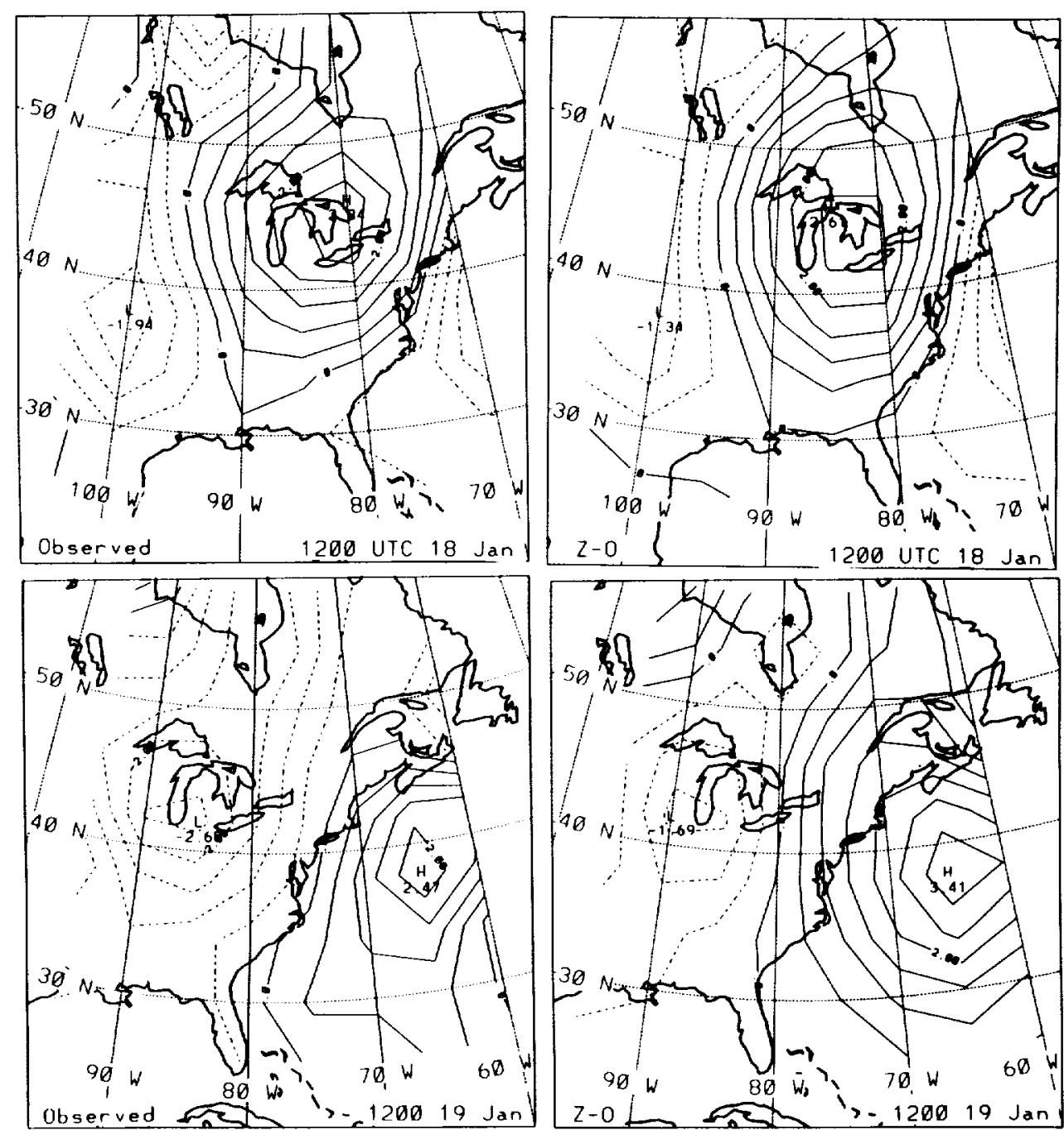

FiG. 6. Near-surface observed (left) and Z-O (right) height tendencies for 1200 UTC 18 January and 1200 UTC 19 January 1979. Increment and units are $0.50 \times 10^{-3} \mathrm{~m} \mathrm{~s}^{-1}$.

tities at the anticyclone center and/or the small Laplacians to be expected from their nearly uniform horizontal distributions.

Examining the two individual map times previously discussed, the midpoint of vigorous anticyclone development ( 1200 UTC 18 January) was marked by large height increases $\left(2.21 \times 10^{-3} \mathrm{~m} \mathrm{~s}^{-1}\right)$. The most significant forcing terms (VADV, TADV, and ADIA) were also large at this time. At 1200 UTC 19 January a small positive total tendency was evident $(0.54$ $\times 10^{-3} \mathrm{~m} \mathrm{~s}^{-1}$ ), due primarily to closer balance between reduced adiabatic warming and anticyclonic vorticity and cold-air advections. Failure to obtain a negative value for the total tendency at this time is most likely due to errors in the calculations of the individual forcing terms, which are more acutely felt when the grid point of interest is near the zero tendency isopleth.

\section{c. Vertical profiles}

Clearly, much of the forcing of near-surface height tendencies occurs as a result of processes well above the surface. These contributions are examined for the two map times previously discussed using vertical profiles of quantities contributing to each forcing term at the anticyclone center.

Figure 9 shows vertical profiles of relative vorticity and absolute vorticity advection. The relative vorticity during anticyclone development ( 18 January) was positive above $750 \mathrm{mb}$ with a maximum at $400 \mathrm{mb}$. During the decay phase ( 19 January), the positive relative vorticity values were smaller with the maximum elevated to $200 \mathrm{mb}$. Negative values extended through a deeper layer from the surface to $500 \mathrm{mb}$. The cyclonic vorticities evident in the upper portion of these profiles can be explained by recalling the position of the anticy- 

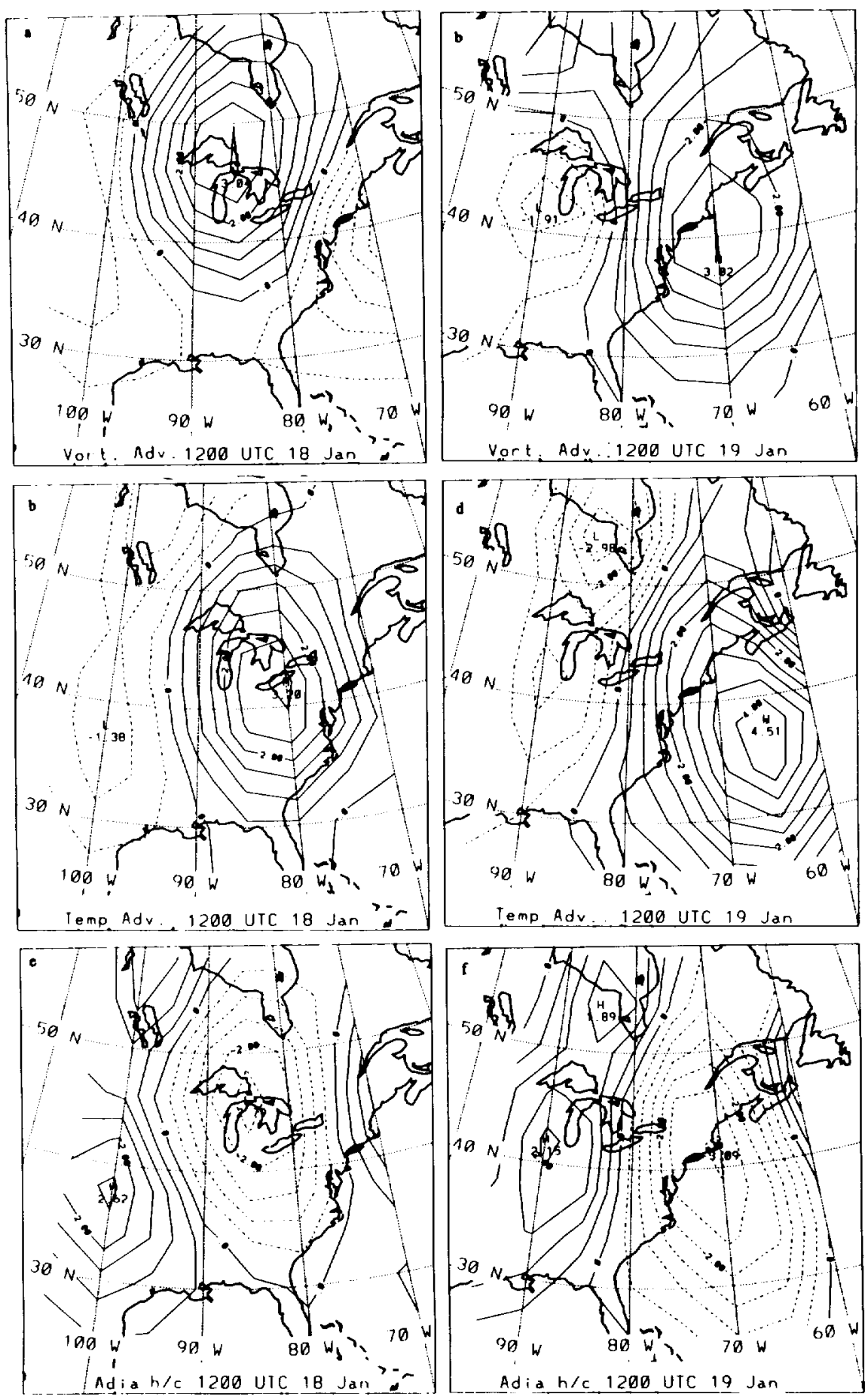

FIG. 7. Contribution to the total $\mathrm{Z}-\mathrm{O}$ height tendency due to horizontal vorticity advection (upper), horizontal temperature advection (middle), and adiabatic heating/cooling (lower) for 1200 UTC 18 January (left-hand panels) and 19 January 1979 (right-hand panels). Increment and units are $0.50 \times 10^{-3} \mathrm{~m} \mathrm{~s}^{-1}$.

clone relative to the upper-air flow. Examining Figs. $1-5 d$, one sees that the anticyclone was initially located under a cyclonic curvature region and, more impor- tantly, throughout the period was located on the cyclonic side of the jet. The vertical profiles of vorticity advection show anticyclonic vorticity advection 
TABLE 1. Near-surface mean absolute values (MAV, $10{ }^{3} \mathrm{~m} \mathrm{~s}$ ') and correlation coefficients (COR) for 0000 UTC 18 January through 0000 UTC 20 January. AVG represents the value averaged over the five map times. DIFF represents the percentage difference between $O B S$ and $Z-O$ MAV values, that is. IOO[IOBSMAV - (Z-OMAV)]/OBSMAV\}.

\begin{tabular}{lllrl}
\hline \hline & \multicolumn{2}{c}{ MAV } & & \\
\cline { 2 - 3 } & Z-O & OBS & DIFF & COR \\
\hline 0000 UTC 18 January & 0.747 & 0.783 & 5 & 0.943 \\
1200 UTC 18 January & 0.895 & 0.957 & 6 & 0.935 \\
OOO0 UTC 19 January & 0.773 & 1.042 & 26 & 0.786 \\
1200 UTC 19 January & 0.880 & 0.938 & 6 & 0.892 \\
0000 UTC 20 January & 0.705 & 1.081 & 35 & 0.911 \\
48-h AVG & 0.800 & 0.960 & 17 & 0.893 \\
\hline
\end{tabular}

(AVA) throughout the column during development, with a maximum at $300 \mathrm{mb}$, similar to the results of Dallavalle and Bosart (1975). By 19 January the AVA had decreased markedly, with weak positive values apparent above $250 \mathrm{mb}$. The temporal changes in AVA that were evident over the anticyclonic center are consistent with a tilted baroclinic wave. As the wave developed and then decayed, the upper-air ridge and the area of minimum vorticity in the upper troposphere overtook the surface anticyclone, resulting in a de-

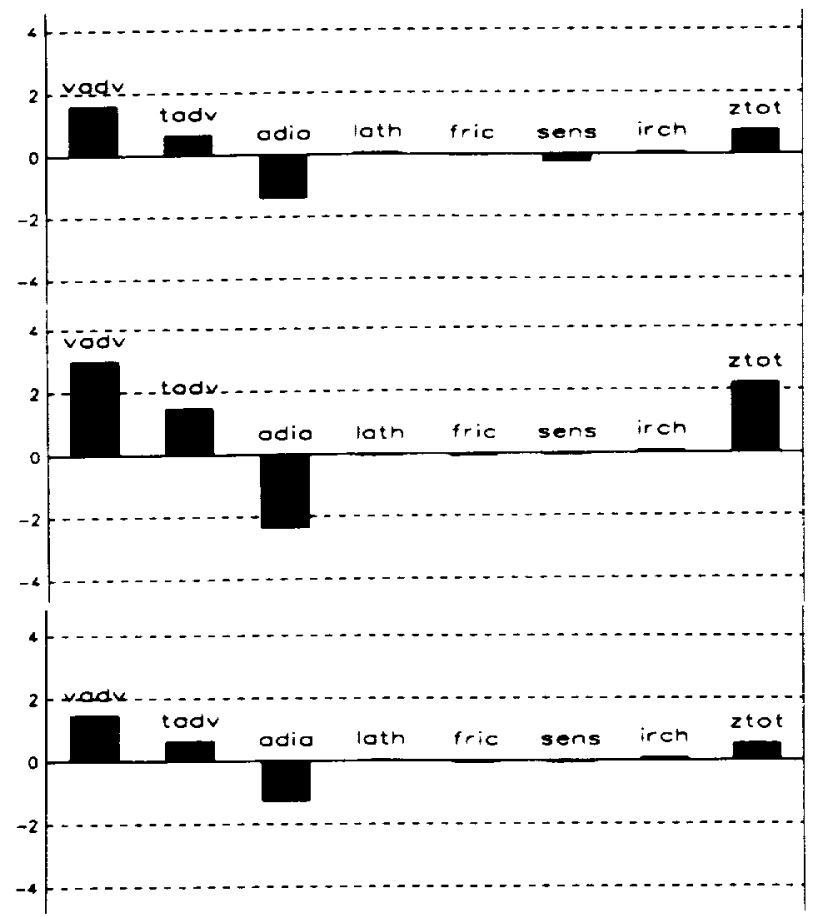

FIG. 8. Total and individual term contributions for the $\mathrm{Z}-\mathrm{O}$ equation height tendency $\left(10^{-3} \mathrm{~m} \mathrm{~s}^{-1}\right)$ at the anticyclone center for the 48-h average (top), 1200 UTC 18 January (middle), and 1200 UTC 19 January 1979 (bottom)
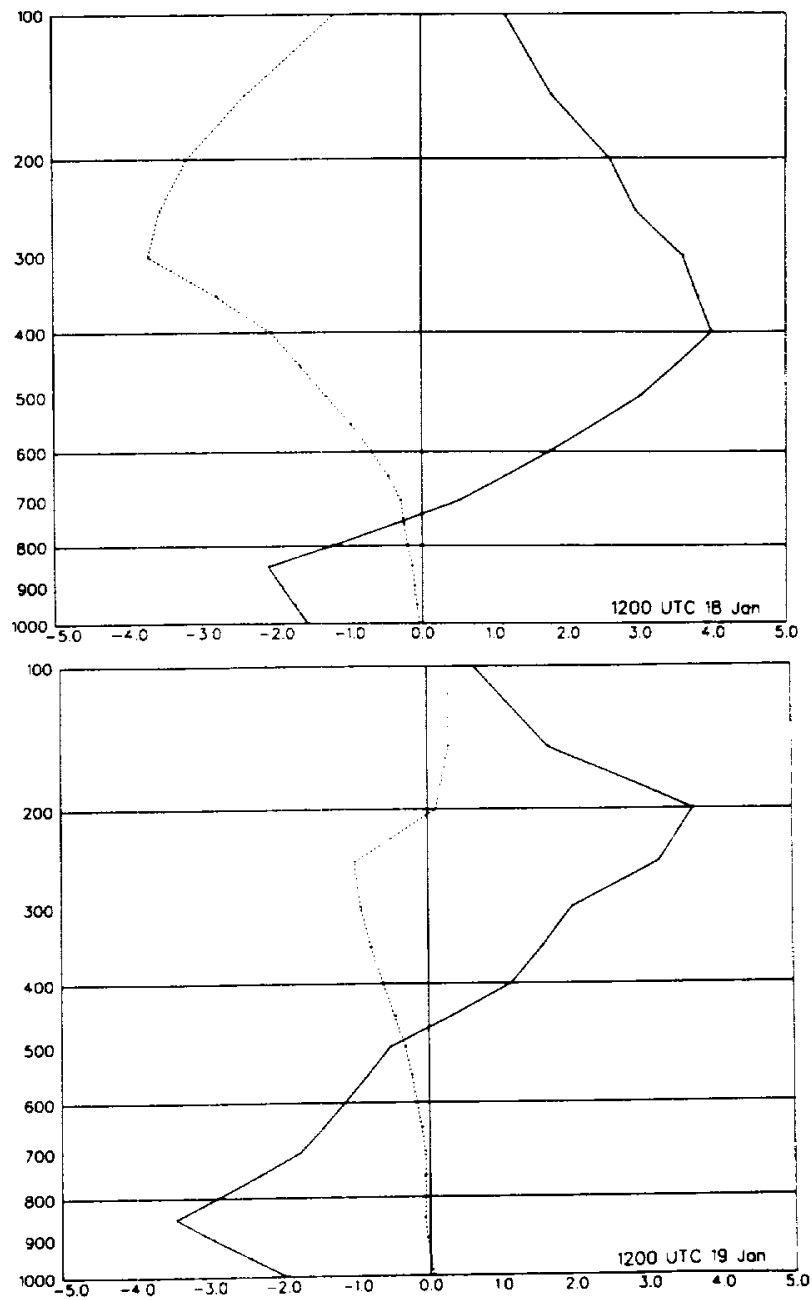

Fig. 9. Vertical protiles of relative vorticity $\left(10^{s} s^{-1}\right.$, solid) and horizontal vorticity advection $\left(10^{-4} \mathrm{~s}^{-2}\right.$, dashed) for 1200 UTC 18 January and 1200 UTC 19 January 1979 at the anticyclone center Ordinate is pressure in millibars.

crease in vertically integrated AVA above the anticyclone.

Figure 10 shows vertical profiles of temperature advection for the anticyclone center. Similar to the vorticity advection, the temperature advection profiles show the forcing due to cold-air advection to be strongest in the upper troposphere/lower stratosphere. These results are similar to those of Bodurtha (1952) and Fleagle (1947). The profiles also show during anticyclogenesis ( 1200 UTC 18 January) a secondary coldair advection maximum in the boundary layer. By 1200 UTC 19 January, decreased upper-level cold-air advection was accompanied by lower-troposphere warm-air advection, thus reducing the integrated cold-air advection.

Figure 11 displays vertical profiles of the product of the static stability and vertical motion $(S \omega)$. Note that 

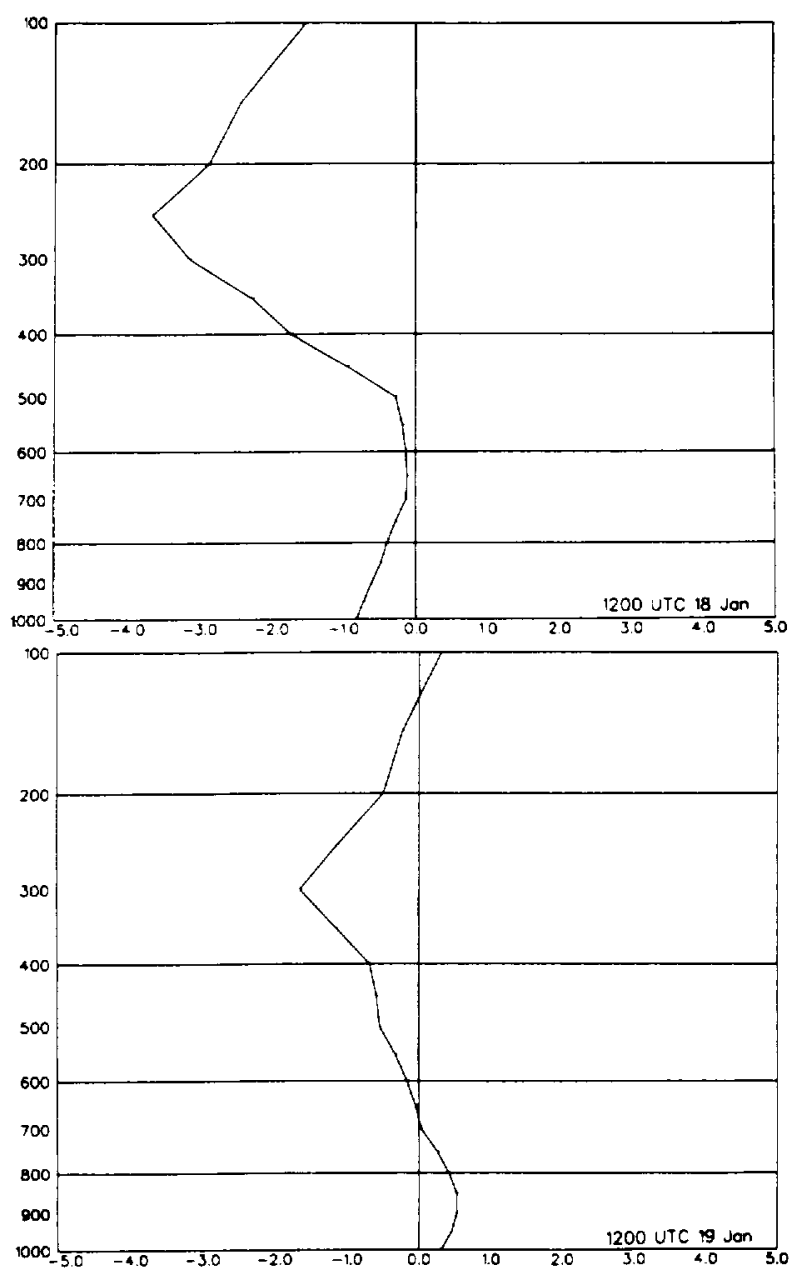

FlG. 10. As in Fig. 9 with vertical profile of horizontal temperature advection $\left(10^{4} \mathrm{~K} \mathrm{~s}^{1}\right)$.

these profiles are opposite in sign to the profiles for the temperature advection. During anticyclogenesis $S \omega$ exhibits a maximum at $300 \mathrm{mb}$, where increasing $S$ values I $S$ increases rapidly above $300 \mathrm{mb}$, see Lupo et al. (1992, Fig. 23)] are coupled with sufficiently strong downward motions. During the decay phase, weakened vertical motions resulted in smaller $S \omega$ values. These profiles indicate subsidence and adiabatic warming over the anticyclone that decreased near-surface height tendencies throughout the development and decay of the anticyclone.

The vertical profiles of friction and sensible heating ( not shown) yield nonzero values below $850 \mathrm{mb}$ only, with friction and sensible heating yielding tendencies in accordance with the results shown in Fig. 8. Profiles of latent heat release and infrared cooling (also not shown) are zero for the former and are consistently negative for the latter, but they are an order of magnitude smaller than the temperature advection throughout the column.

\section{Discussion}

A diagnosis of a winter North American anticyclone that occurred from 0000 UTC 18 January to 0000 UTC 20 January 1979 was performed using the near-surface height tendencies derived from the Zwack-Okossi equation.

Using horizontal fields and vertical profiles, the results demonstrate that anticyclonic vorticity advection, dominated by upper-tropospheric-lower-stratospheric advections, was the most significant contributor to the total near-surface height increases found upstream, within, and downstream from the anticyclone center. Temperature advection, dominated by cold-air advection at the same upper levels, was the next most significant development term. Thus, dynamic and thermodynamic transport processes in the upper troposphere and lower stratosphere had a profound influence on the anticyclone's development. This is consistent with the results of Austin and Shapiro (1951) and Bo-
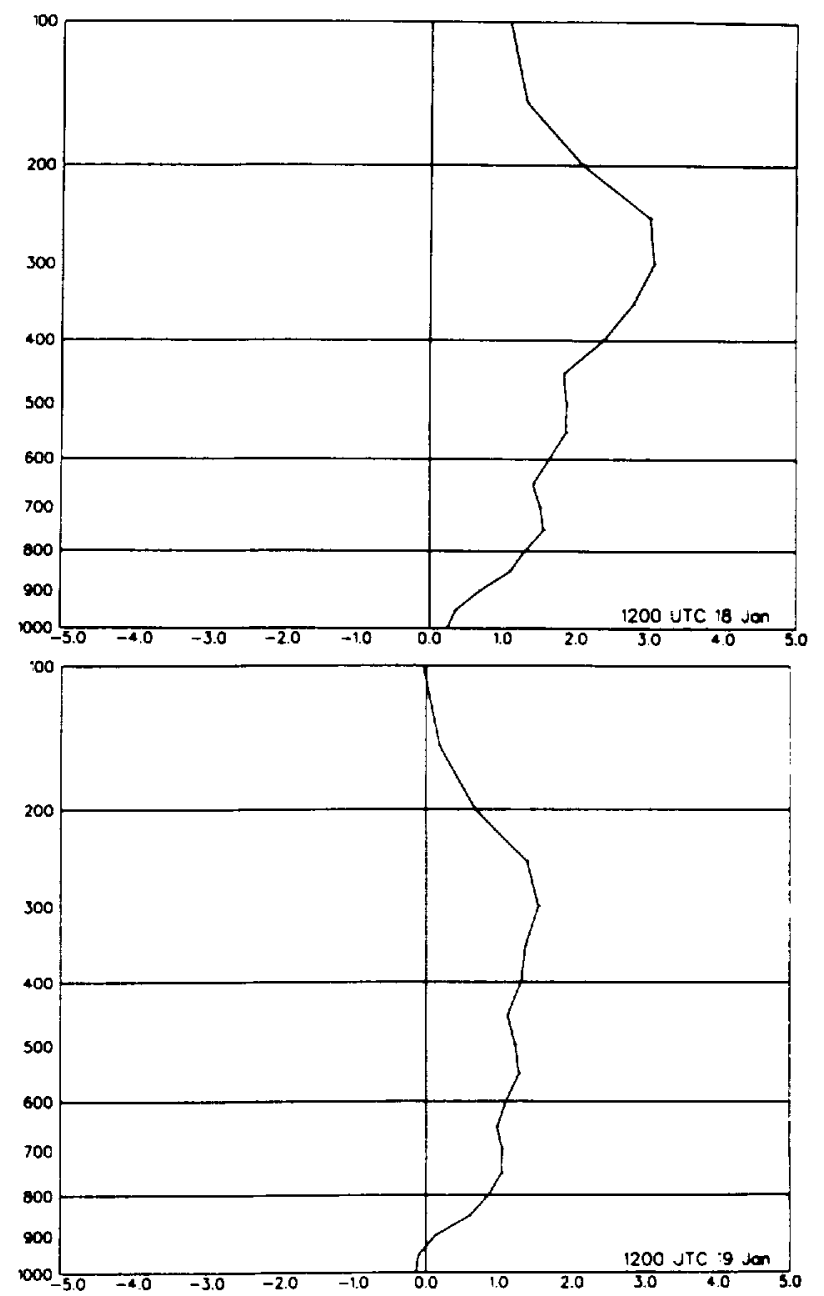

Fig. 11. As in Fig. 9 with vertical profile of adiabatic warming $\left(S \omega, 10{ }^{4} \mathrm{Ks}{ }^{1}\right)$. 
durtha (1975), who found that mass increases associated with anticyclone pressure increases are most strongly contributed by the upper troposphere/lower stratosphere. Further, the dominance of the two advection processes for the modest anticyclone studied here corresponds to similar results to be inferred from Tan and Curry (1993) for a very strong winter anticyclone. The adiabatic term, because of adiabatic warming in the descending air, contributed negatively to the development of the anticyclone and was the same order of magnitude as the vorticity and temperature advection terms. Boundary layer sensible heating, latent heat release, boundary layer friction, and infrared cooling made only minor contributions to anticyclone development. The latter, perhaps surprising, result is similar to that found by Tan and Curry (1993), both of which stand in contrast to the model results of Curry (1987).

Finally, comparison with the results of Lupo et al. (1992) reveals that aside from the absence of a latent heat release influence, the large-scale forcing mechanisms important in the development of this migrating anticyclone case are the same, although of opposite sign, as those for migrating cyclones. Horizontal vorticity and temperature advection, both of which maximize at upper levels, and adiabatic heating (cooling) are dominant forcing processes for both phenomena.

Acknowledgments. The authors are grateful to Dayton Vincent, John Snow, and the referees for their very helpful comments on this work and to Helen Henry for typing the manuscript. This research was sponsored by the National Aeronautics and Space Administration under Grants NAG8-764 and NAG8-915.

\section{REFERENCES}

Austin, J. M., and R. Shapiro, 1951: Tropospheric and stratospheric temperature changes associated with pressure changes. J. Meteor., 8, 191-195.
Baker, W. E., 1983: Objective analysis and assimilation of observational data from FGGE. Mon. Wea. Rev., 111, 328-342.

Bodurtha. F. T., 1952: An investigation of anticyclogenesis in Alaska. J. Meteor., 9, 118-125.

Bowling, S. A., T. Ohtake, and C. S. Benson, 1968: Winter pressure systems and ice fog in Fairbanks, Alaska. J. Appl. Meteor., 7, 961-968.

Boyle, J. S., and L. F. Bosart, 1983: A cyclone-anticyclone couplet over North America: An example of anticyclone evolution. Mon. Wea. Rev., 111, 1025-1045.

Curry, J., 1983: On the formation of continental polar air. J. Atmos. Sci., 40, 2278-2292.

- 1987: The contribution of radiative cooling to the formation of cold-core anticyclones. J. Atmos. Sci. 44, 2575-2592.

Dallavalle, J. P., and L. F. Bosart, 1975: A synoptic investigation of anticyclogenesis accompanying North American polar air outbreaks. Mon. Wea. Rev., 103, 941-957.

Fleagle, F, G., 1947: The fields of temperature, pressure, and threedimensional motion in selected weather situations. J. Meteor., 4, $165-185$

Harshvardhan, R. Davies, D. A. Randall, and T. G. Corsetti, 1987: A fast radiation parameterization for atmospheric circulation models. J. Geophys. Res., 92, 1009-1016.

Lupo, A. R., P. J. Smith, and P. Zwack, 1992: A diagnosis of the explosive development of two extratropical cyclones. Mon. Wea. Rev., 120, $1490-1523$

Petterssen, S., 1956: Weather Analysis and Forecasting. Vol. 1. McGraw-Hill, $428 \mathrm{pp}$.

Ramanathan, V., E. J. Pitcher, R. C. Malone, and M. L. Blackmon, 1983: The response of a spectral general circulation model to refinements in radiative processes. J. Atmos. Sci., 40, 605-630.

Sasamori, T., 1968: The radiative cooling calculation for application to general circulation experiments. J. Appl. Meteor., 7, 721729.

Tan, Y.-C., and J. Curry, 1993: A diagnostic study of the evolution of an intense North American anticyclone during winter 1989. Mon. Wea. Rev, 121, 961-975.

Tsou, C.-H., P. J. Smith, and P. M. Pauley, 1987: A comparison of adiabatic and diabatic forcing in an intense extratropical cyclone system. Mon. Wea. Rev., 115, 763-786.

Wexler, H., 1951: Anticyclones. Compendium of Meteorology, T. F. Malone, Ed., Amer. Meteor. Soc., 621-628.

Zwack, P., and B. Okossi, 1986: A new method for solving the quasigeostrophic omega equation by incorporating surface pressure tendency data. Mon. Wea. Rev., 114, 655-666. 